\title{
Tyrosine Phosphorylation and Regulation of the AMPA Receptor by Src Family Tyrosine Kinases
}

\author{
Takashi Hayashi and Richard L. Huganir \\ Department of Neuroscience, Howard Hughes Medical Institute, Johns Hopkins University School of Medicine, Baltimore, Maryland 21205
}

\begin{abstract}
Phosphorylation of AMPA receptors is a major mechanism for the regulation of receptor function and underlies several forms of synaptic plasticity in the CNS. Although serine and threonine phosphorylation of AMPA receptors has been well studied, the potential role of tyrosine phosphorylation of AMPA receptors has not been investigated. Here, we show that the GluR2 subunit of AMPA receptors is tyrosine phosphorylated in vitro and in vivo by Src family tyrosine kinases on tyrosine 876 near its $\mathrm{C}$ terminus. In addition, GluR agonist treatment of cultured cortical neurons increased phosphorylation of tyrosine 876. The association with GluR2-interacting molecules GRIP1/2 was decreased by tyrosine phosphorylation of GluR2, whereas PICK1 interaction was not influenced. Moreover, mutation of tyrosine 876 eliminated AMPA- and NMDA-induced internalization of the GluR2 subunit. These data indicate that tyrosine phosphorylation of tyrosine 876 on the GluR2 C terminus by Src family tyrosine kinases is important for the regulation of AMPA receptor function and may be important for synaptic plasticity.
\end{abstract}

Key words: AMPA; kinase; phosphorylation; receptor; tyrosine; glutamate; Src

\section{Introduction}

Glutamate is the major excitatory neurotransmitter in the mammalian CNS. The ionotropic glutamate receptors are classified into several groups: AMPA, kainate (KA), $\delta$, and NMDA receptors. The AMPA receptor is a ligand-gated cation channel that mediates the fast component of EPSCs in the CNS. The AMPA receptor consists of four types of subunits: GluR1, -2, -3, and -4 (Hollman and Heinemann, 1994; Roche et al., 1994). Recent studies have shown that serine/threonine phosphorylation of AMPA receptor subunits play critical roles in the regulation of synaptic plasticity (Swope et al., 1999; Soderling and Derkach, 2000; Song and Huganir, 2002). Protein phosphorylation of AMPA receptors has been shown to modulate AMPA receptor ion channel properties as well as the membrane trafficking of AMPA receptors to the postsynaptic membrane (Song and $\mathrm{Hu}-$ ganir, 2002). Phosphorylation of serines 831 and 845 in the GluR1 subunit by calcium-calmodulin-dependent protein kinase II (CaMKII) and cAMP-dependent protein kinase, respectively, regulates the ion channel properties and synaptic trafficking of GluR1-containing AMPA receptors during hippocampal long-term potentiation (LTP) (Roche et al., 1996; Barria et al., 1997; Mammen et al., 1997; Derkach et al., 1999; Banke et al., 2000; Lee et al., 2000; Esteban et al., 2003). Furthermore, dephos-

\footnotetext{
Received March 5, 2004; revised May 11, 2004; accepted May 14, 2004.

This work was supported by research grants from the Howard Hughes Medical Institute, National Institutes of Health, and Toyobo Biotechnology Foundation. We are grateful to C. Doherty for antibody preparation, L. Ding for cultured neuron preparation, D. Bury for assistance, and H. Okuno and G. Thomas for valuable discussion.

Under a licensing agreement between Upstate Group, Inc. and The Johns Hopkins University, R.L.H. is entitled to a share of royalty received by the University on sales of products described in this article. R.L.H. is a paid consultant to Upstate Group, Inc. The terms of this arrangement are being managed by The Johns Hopkins University in accordance with its conflict of interest policies.

Correspondence should be addressed to Dr. Richard L. Huganir, Howard Hughes Medical Institute, Johns Hopkins University Medical School, 725 North Wolfe Street, PCTB 904B, Baltimore, MD 21205. E-mail: rhuganir@jhmi.edu. DOI:10.1523/JNEUROSCI.0799-04.2004

Copyright $\odot 2004$ Society for Neuroscience $\quad$ 0270-6474/04/246152-09\$15.00/0
}

phorylation of these sites on GluR1 by protein phosphatases during long-term depression (LTD) regulates receptor function and trafficking (Kameyama et al., 1998; Lee et al., 1998, 2000, 2003). Moreover, mutation of these sites in mice decreases the expression of hippocampal LTP and LTD and produces defects in memory retention (Lee et al., 2003). Phosphorylation of serine 880 on the GluR2 subunit regulates its interaction with the PDZ [postsynaptic density-95/Discs large/zona occludens-1] domain containing proteins GRIP1/2 and PICK1 and is critical for the expression of cerebellar and hippocampal LTD (Chung et al., 2000, 2003; Matsuda et al., 2000; Kim et al., 2001).

In contrast to serine and threonine phosphorylation, the role of tyrosine phosphorylation of AMPA receptors has not been investigated. Several studies have reported that protein tyrosine kinases (PTKs) regulate long-term changes of synaptic transmission at glutamatergic synapses (Boxall and Lancaster, 1998). PTK inhibitors such as genistein, herbimycin A, and lavendustin A have been reported to block the induction of hippocampal LTP and cerebellar LTD (O'Dell et al., 1991; Boxall and Lancaster, 1998). In addition, some PTK-deficient mice have various neural deficits including impaired LTP and deficient learning. For example, mice with a targeted deletion of the Src family tyrosine kinase Fyn have deficient hippocampal LTP, learning, and memory (Grant et al., 1992; Miyakawa et al., 1997; Kitazawa et al., 1998). Here, we report that the GluR2 subunit of AMPA receptor is tyrosine phosphorylated on its C-terminal domain by Src family PTKs. Phosphorylation of this site is regulated by glutamate and is critical for the regulated endocytosis of GluR2. These data suggest that tyrosine phosphorylation may play crucial roles in the proper localization and trafficking of AMPA receptors.

\section{Materials and Methods}

Generation of anti-GluR2 C-terminal phosphotyrosine-specific antibodies. Anti-GluR2CPY antibodies (JH3410) were raised against the synthetic 
phosphopeptide KQNFATpYKEGpYNVpYGIESVKI corresponding to aa 864-883 of GluR2, with three phosphotyrosine residues. AntiGluR2CPY antibodies were affinity purified from antisera by sequential chromatography using Affi-Gel (Bio-Rad, Hercules, CA) columns covalently linked to BSA-conjugated unphosphorylated (KQNFATYKEGYNVYGIESVKI) and tyrosine-phosphorylated GluR2 C-terminal peptides. Anti-GluR2 N-terminal monoclonal antibody (MAB397) was purchased from Chemicon (Temecula, CA). Anti-Src, anti-Fyn, antiLyn, anti-phosphotyrosine (PY20), and anti-tubulin antibodies were from Santa Cruz Biotechnology (Santa Cruz, CA). Blocking and washing solutions for Western blotting were 5\% BSA in TBS (50 mm Tris- $\mathrm{HCl}, \mathrm{pH}$ 7.5, and $150 \mathrm{~mm} \mathrm{NaCl}$ ) and in TBS containing $0.05 \%$ Triton X-100 for anti-phosphotyrosine antibody and $0.5 \%$ skim milk and $0.1 \%$ Tween 20 in TBS for the other antibodies.

Primary neuron culture, transfection, stimulation, rodent brain lysate, and biotinylation. High-density cortical cultured neurons and lowdensity hippocampal cultured neurons were prepared as described previously (Goslin and Banker, 1991). Cortical cultured neurons $\left(10^{6}\right.$ cells per lane) were used between 3 and 4 weeks after plating for biochemical experiments. At 14-16 d in vitro (DIV), cortical culture neurons on coverslips were used for green fluorescent protein (GFP)-GluR2 transfection. HEK 293T cells $\left(10^{7}\right.$ cells per lane) were transfected with pRK5Src, pRK5-Lyn [cytomegalovirus (CMV) promoter], and wild-type and mutant pRK5-GluR2 (CMV promoter) by calcium phosphate method as described (Hayashi et al., 1999). For stimulation of AMPA receptors, cortical culture neurons were washed twice with $3 \mathrm{ml}$ of extracellular artificial CSF solution containing 15 mM HEPES, pH 7.5, $140 \mathrm{~mm} \mathrm{NaCl}$, $5 \mathrm{~mm} \mathrm{KCl}, 1 \mathrm{~mm} \mathrm{MgCl}_{2}, 5 \mathrm{~mm}$ glucose, $0.5 \mathrm{~mm}$ EDTA, and $0.12 \%$ $\mathrm{NaHCO}_{3}$. Then, cortical culture neurons were incubated in the same buffer at $37^{\circ} \mathrm{C}$ for $30 \mathrm{~min}$ before stimulation with GluR agonists. TTX ( 5 $\mu \mathrm{M})$ was added to inhibit neuronal activity. Cells were lysed with radioimmunoprecipitation assay (RIPA) buffers containing $10 \mathrm{~mm}$ Tris- $\mathrm{HCl}$, pH7.5, $150 \mathrm{~mm} \mathrm{NaCl}, 1 \mathrm{~mm}$ EDTA, 1 mм $\mathrm{Na}_{3} \mathrm{VO}_{4}, 1 \%$ Triton X-100, $0.1 \%$ SDS, $0.1 \%$ sodium deoxycholate, $10 \mu \mathrm{g} / \mathrm{ml}$ aprotinin, and $10 \mu \mathrm{g} / \mathrm{ml}$ leupeptin. Each area of C57BL/6 mice brain was homogenized and lysed in buffer containing $50 \mathrm{~mm}$ Tris- $\mathrm{HCl}, \mathrm{pH} 8.0,150 \mathrm{~mm} \mathrm{NaCl}, 20 \mathrm{~mm}$ EDTA, $1 \mathrm{~mm} \mathrm{Na} \mathrm{VO}_{4}, 1 \%$ Triton X-100, $10 \mu \mathrm{g} / \mathrm{ml}$ aprotinin, and 10 $\mu \mathrm{g} / \mathrm{ml}$ leupeptin. Samples were analyzed by $7.5 \%$ SDS-PAGE, followed by immunoblotting. For surface biotinylation, cortical culture neurons were cooled on ice, washed twice with ice-cold PBS containing $1 \mathrm{~mm}$ $\mathrm{CaCl}_{2}$ and $5 \mathrm{mM} \mathrm{MgCl}_{2}$, and then incubated with PBS containing $1 \mathrm{~mm}$ $\mathrm{CaCl}_{2}, 5 \mathrm{mM} \mathrm{MgCl}_{2}$, and $1 \mathrm{mg} / \mathrm{ml}$ Sulfo-NHS-LC-Biotin (Pierce, Rockford, IL) for $20 \mathrm{~min}$ at $4^{\circ} \mathrm{C}$. Unreacted biotinylation reagent was washed three times with ice-cold TBS. Cortical culture neurons were harvested in RIPA buffer. Homogenates were centrifuged at $15,000 \times g$ for $20 \mathrm{~min}$ at $4^{\circ} \mathrm{C}$. The resulting supernatant was incubated with NeutrAvidin beads (Pierce) for $3 \mathrm{hr}$ at $4^{\circ} \mathrm{C}$. Precipitates were analyzed by immunoblotting with each antibody.

Immunocytochemical experiments. Anti-GFP antibodies (JH4030) were raised against a GFP fusion protein. GFP-GluR cluster numbers were automatically counted and analyzed with MetaMorph software (Universal Imaging, West Chester, PA) after setting a threshold of fluorescent intensity that was slightly higher than that in the dendritic shaft. The number of clusters was normalized with the dendritic length after all dendritic branches in an image were traced and measured manually. The upper threshold limit for this selection was used to exclude the cell body and proximal dendritic shafts, which have much larger area than spines (Liao et al., 1999).

Internalized GFP-GluR2 and endogenous GluR1 were selectively visualized as follows. Surface GFP-GluR2 or GluR1 was labeled in living neurons at $10^{\circ} \mathrm{C}$ for a 20 min incubation with anti-GFP or anti-GluR1 N terminus antibodies. After washout of the excess antibodies, culture neurons were treated with $100 \mu \mathrm{M}$ AMPA or $50 \mu \mathrm{M}$ NMDA at $37^{\circ} \mathrm{C}$. After the stimulation, neurons were washed with $4 \%$ sucrose in PBS twice, fixed with $4 \%$ paraformaldehyde and $4 \%$ sucrose in PBS (room temperature; $20 \mathrm{~min}$ ), and surface remaining anti-GFP or anti-GluR1 $\mathrm{N}$ terminus antibodies were blocked with anti-rabbit IgG goat antibody $\mathrm{F}\left(\mathrm{ab}^{\prime}\right) 2$ fragment (Jackson Immunoresearch, West Grove, PA). Then, fixed neurons were permeabilized with $0.1 \%$ Triton $\mathrm{X}-100\left(4^{\circ} \mathrm{C} ; 10 \mathrm{~min}\right)$ for GFP-
GluR2 or with methanol $\left(-20^{\circ} \mathrm{C} ; 1 \mathrm{~min}\right)$ for GluR1. Coverslips were blocked in $10 \%$ normal donkey serum in PBS at $4^{\circ} \mathrm{C}$ overnight, and then internalized GFP-GluR2 was visualized by staining with Cy3-conjugated anti-rabbit IgG (Jackson Immunoresearch) diluted in 10\% normal donkey serum in PBS as secondary antibodies. Fluorescence images were acquired using a Photometrics CCD camera and quantified with MetaMorph. The fluorescence intensity averages of Cy3-red and GFP-green signals in dendrite regions in indicated numbers of different neurons were measured. Red fluorescence intensity indicative of internalization was divided by green fluorescence intensity to control for GFP-GluR2 protein expression. Units of internalization were measured as ratio of red/green fluorescence normalized to untreated controls.

\section{Results}

\section{Tyrosine phosphorylation of GluR2 C terminus in rodent brain lysates}

Previous studies have shown that Src family PTKs can interact with the AMPA receptor GluR2 subunit (Hayashi et al., 1999). To test whether AMPA receptor subunits were tyrosine phosphorylated, we prepared mouse brain lysates, immunoprecipitated individual AMPA receptor subunits, and analyzed them for phosphotyrosine content by immunoblotting using anti-phosphotyrosine antibody. As shown in Figure 1, the GluR2 and GluR3 subunits were tyrosine phosphorylated, whereas, in contrast, tyrosine phosphorylation of GluR1 and GluR4 were not detected (Fig. 1A). There are several tyrosine residues in the intracellular regions of the AMPA receptor subunits that are potential tyrosine phosphorylation sites. One tyrosine located between transmembrane domain (TMD) 1 and TMD 2 and another tyrosine just after TMD 4 are conserved in all four subunits GluR1-4. In addition, there are three additional tyrosine residues in the $\mathrm{C}$ terminus of GluR2 and four residues in GluR3. The three most C-terminal tyrosines are conserved between GluR2 and GluR3 (Fig. $1 B$ ). These three C-terminal tyrosines in GluR2/3 fit known consensus sites for tyrosine kinases (Songyang and Cantley, 1998; Songyang, 2001). Receptor-type PTKs such as the epidermal growth factor receptor or Trk family PTKs prefer the amino acid sequence Glu-Tyr-hydrophobic residues (E-Y- $\Phi)$, whereas nonreceptor-type PTKs such as Src family PTK prefer Ile/Val-Tyr-Glu/Gly/Ala (I/V-Y-E/G/A). The sequence around tyrosine 876 of GluR2 (V-Y-G) is completely in accordance with the target sequence of nonreceptor-type PTKs, suggesting that tyrosine 876 residue may be phosphorylated. To test the possibility that this region is tyrosine phosphorylated, phosphoantibodies were generated against this region using a synthetic peptide containing phosphotyrosines in place of all three tyrosine residues within the GluR2 C-terminal 20 amino acid (antiGluR2CPY) (Fig. $1 B$ ). The antibody was sequentially purified on a phosphotyrosine GluR2 peptide and non-phospho-GluR2 peptide columns.

To analyze whether GluR2 was phosphorylated on these tyrosines, brain lysates from mouse cortex, hippocampus, and cerebellum were immunoblotted with the anti-GluR2CPY or antiGluR2 antibodies. Western blotting analysis detected tyrosine phosphorylation of the GluR2 C terminus in all of these three brain regions (Fig. 1C). The strongest tyrosine phosphorylation was detected in lysates from cortex, whereas expression of GluR2 protein itself was largest in the hippocampus. Weak tyrosine phosphorylation in cerebellum was detected upon longer exposure. Preabsorption of anti-GluR2CPY antibodies with phosphopeptide prevented immunorecognition. Moreover, $\lambda$ phosphatase treatment also eliminated recognition of GluR2 by anti-GluR2CPY antibodies, indicating the recognition was phospho-specific. Using immunoprecipitation experiments, we estimated that $1-2 \%$ of GluR2 was 
tyrosine phosphorylated in the mouse whole-brain lysate (data not shown).

\section{Phosphorylation of GluR2 C-terminal region by Src family PTKs}

Because the sequence surrounding tyrosine 876 of GluR2 fit the consensus sequence for Src family PTKs, we used the anti-GluR2CPY antibodies to examine the tyrosine phosphorylation of GluR2 by PTKs in transfected HEK 293T cells. Coexpression of GluR2 and the Src family PTK Lyn demonstrated that Lyn could phosphorylate the GluR2 C-terminal tyrosines (Fig. $2 A$, top). The signal was abolished by absorption of anti-GluR2CPY antibodies with their phosphopeptide antigen, whereas corresponding non-phosphopeptide absorption had no effect on antibody recognition (Fig. $2 \mathrm{~A}$, middle). In addition, $\lambda$ phosphatase treatment eliminated the recognition of GluR2 by anti-GluR2CPY antibodies, indicating the recognition was phospho-specific (Fig. $2 \mathrm{~A}$, bottom). The Src family PTKs Src and Fyn were also found to phosphorylate the GluR2 C terminus (data not shown). In contrast, the nonreceptor-type PTKs Fak and Pyk2 did not phosphorylate GluR2 in transfected HEK 293 T cell (data not shown). Because the GluR2 C terminus has a similar sequence with GluR3, the corresponding tyrosine sites of GluR3 may also be phosphorylated. To investigate this possibility, GluR2 or GluR3 were coexpressed with Src PTK in HEK 293T cells, and cell lysates were immunoblotted with anti-GluR2CPY antibodies. Under these conditions, our antibodies did not recognize tyrosine phosphorylation of GluR3 (Fig. 2B). The AMPA receptor subunit Cterminal sequences show that the isoleucine at the +2 position of Y876 in GluR2 (pY876G-I) is substituted with threonine in GluR3 (Y881-G-T). The difference may affect the tyrosine phosphorylation by Src family PTKs or the recognition of phosphotyrosine-specific anti-GluR2CPY antibodies.

\section{GluR2 AMPA receptor subunit was \\ phosphorylated at tyrosine $\mathbf{8 7 6}$}

To determine the exact site of tyrosine phosphorylation, three different GluR2 mutants with the individual tyrosine residues mutated to phenylalanine (GluR2Y869F, GluR2Y873F, and GluR2Y876F) were generated by site-directed mutagenesis (Fig. 3A). These mutants were cotransfected with the Src family PTK Lyn into HEK 293T cells, and cell lysates were analyzed by immunoblotting. Cotransfection experiments revealed that mutation of tyrosine 876 , but not tyrosine 869 or 873 , eliminated recognition by the GluR2CPY antibodies (Fig. $3 B$ ), indicating that tyrosine 876 was phosphorylated by the Src family PTKs. It is still possible that tyrosines 869 and 873 are phosphorylated but that the anti-GluR2CPY antibodies do not recognize these phosphotyrosines or that these tyrosine residues are phosphorylated by other PTKs in vivo.

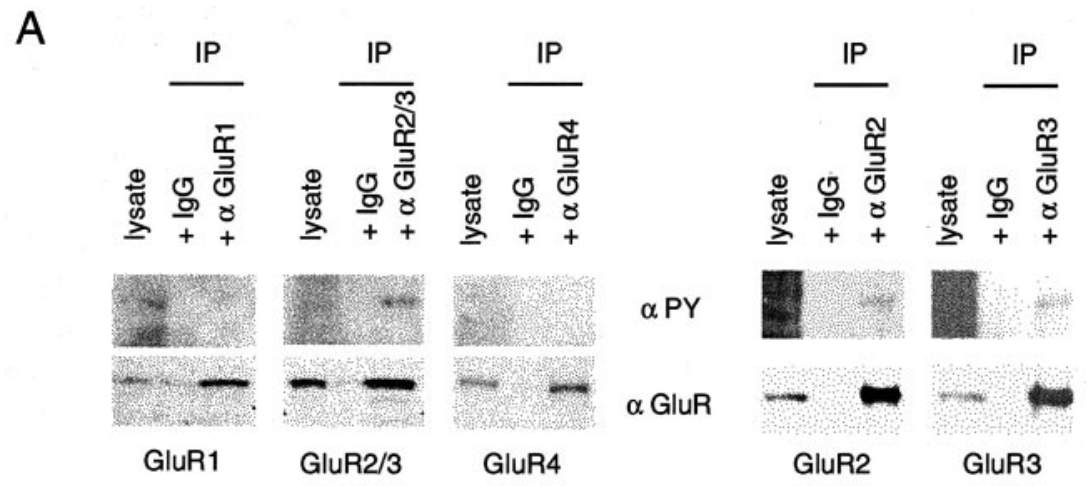

Figure 1. Tyrosine phosphorylation in the GluR2 C-terminal region in rodent brain lysates. A, Tyrosine phosphorylation of each AMPA receptor subunit. Immunoprecipitates were isolated from mouse whole-brain lysates using rabbit lgG or each anti-GluR subunit antibody and were then immunoblotted with anti-phosphotyrosine antibody (PY20) or anti-GluR antibodies recognizing antibodies and its corresponding non-phosphopeptide are shown. C, C-terminal tyrosine-phosphorylated GluR2 in the ysate from mouse cortex $(\mathrm{Cx})$, hippocampus (Hi), or cerebellum $(\mathrm{Cb})$. Brain lysates were immunoblotted with anti-GluR2, antithe antigen phosphopeptide or by $\lambda$ phosphatase treatment but not by preabsorption with the non-phosphopeptide. Antitubulin immunoblot confirmed equal protein loading.

\section{Different regulation of GluR2-interacting molecules by tyrosine phosphorylation of GluR2}

Because tyrosine 876 is within a few amino acids of the GluR2 C-terminal PDZ ligand that binds to the PDZ-containing proteins GRIP1/2 and PICK1, we next investigated whether tyrosine phosphorylation influenced GRIP1/2 and PICK1 binding. The interaction of these molecules with GluR2 was analyzed in HEK 293 T cells cotransfected with PICK1, GRIP1 or -2 , with the Lyn kinase. Coimmunoprecipitation experiments showed that interaction of GluR2 with GRIP1 (Fig. 4A) and GRIP2 (Fig. 4B) was reduced by coexpression with Lyn, compared with coexpression with the kinase-negative form of Lyn. These results indicates that phosphorylation of tyrosine 876 by Src family PTKs significantly impaired the interaction between GluR2 and GRIP1/2. In con- 
A

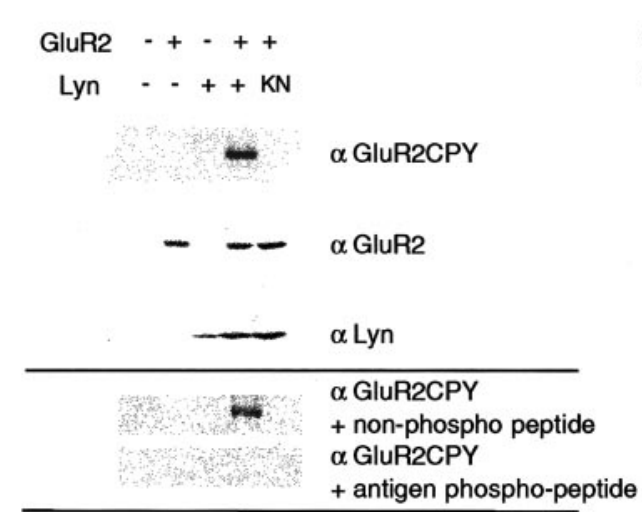

$\lambda$ Phosphatase
B

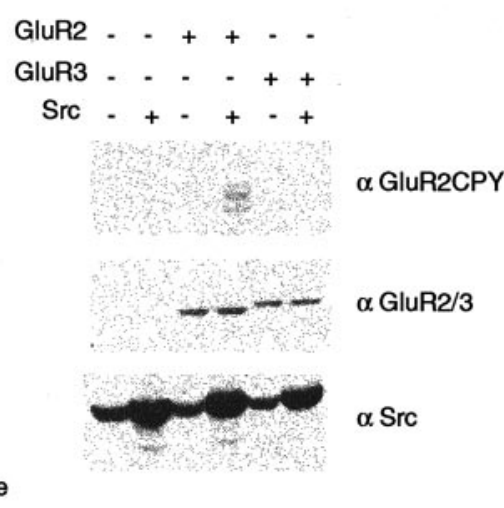

addition, GluR2Y876F still binds to GRIP1 (Fig. 4G), GRIP2 (Fig. 4H), and PICK1 (Fig. $4 I$ ) as well as the GluR2 wild type.

\section{Activation of glutamate receptors stimulated tyrosine phosphorylation of GluR2}

To examine whether tyrosine phosphorylation of GluR2 was regulated by stimulation, we analyzed the modulation of phosphorylation of tyrosine 876 in 3- to 4 -week-old rat cortical cultured neurons. The cultured cortical neurons were stimulated with $100 \mu \mathrm{M}$ glutamate, $100 \mu \mathrm{M}$ AMPA, or $50 \mu \mathrm{M}$ NMDA for $10 \mathrm{~min}$ in the presence of $5 \mu \mathrm{M}$ TTX. Cell lysates were then isolated and immunoblotted with anti-GluR2 or anti-GluR2CPY antibodies (Fig. 5A). Treatment of the cultures with the GluR agonists resulted in a rapid and significant increase of GluR2 C-terminal tyrosine phosphorylation in the cultured cortical neurons. Enhancements of tyrosine phosphorylation were detected within 5 min (data not shown). The GluR agonist-induced increase in tyrosine phosphorylation was observed in calcium-free

Figure 2. Tyrosine phosphorylation of the GluR2 C-terminal region by Src family PTKs. A, C-terminal tyrosine-phosphorylated GluR2 in lysates from HEK 293T cells transfected with plasmids encoding GluR2 and plasmids encoding Src family PTK Lyn or a kinase-negative form of Lyn (KN). Cell lysates were immunoblotted with anti-GluR2CPY antibodies. Expression of each protein was confirmed by protein immunoblots of cell lysates probed with anti-GluR2 or anti-Lyn antibodies (top). Preabsorption experiments with antigen GluR2 C-terminal phosphopeptide or non-phosphopeptide (middle) and $\lambda$ phosphatase treatment experiment (bottom) are shown. B, C-terminal tyrosine phosphorylation of GluR2 and GluR3 in lysates from HEK 293T cells transfected with plasmids encoding GluR2 or GluR3 and plasmids encoding Src. Cell lysates were immunoblotted with anti-GluR2CPY antibodies. Expression of each protein was confirmed by protein immunoblots of cell lysates probed with anti-GluR2/3 or anti-Src antibodies.

\section{A}

[TM4] EFCYKSRAEAKRMKGFCLIPQQSINEAIRTSTVAKN

PQNINPSSSQNSQNFATYKEGYNVYGIESVKI PQNINPSSSQNSQNFATFKEGYNVYGIESVKI PQNINPSSSQNSQNFATYKEGFNVYGIESVKI PQNINPSSSQNSQNFATYKEGYNVFGIESVKI

WT Y $869 \mathrm{~F}$ Y873F Y876F

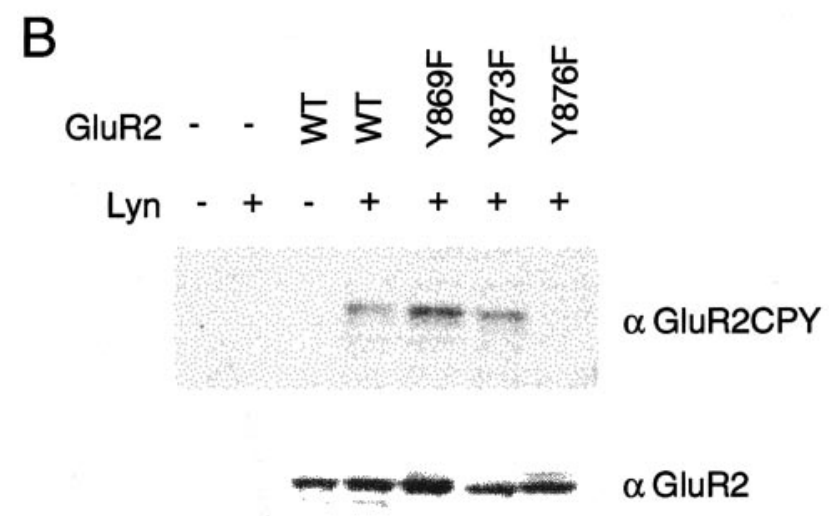

Figure 3. Phosphorylated tyrosine residues in the GluR2 C terminus by Src family PTKs. A, Three single-point mutant GluR2 subunits containing tyrosine to phenylalanine mutations (Y869F, Y873F, and Y876F) were generated. B, C-terminal tyrosine phosphorylation of the GluR2 wild type (WT) and the three GluR2 YF mutants in anti-GluR2 immunoprecipitates from lysates of HEK 293T cells transfected with wild-type or mutant GluR2 with plasmids encoding the Src family PTK Lyn. Cell lysates were immunoprecipitated with anti-GluR2 antibody, followed by immunoblotting with anti-GluR2CPY or anti-GluR2 antibodies.

trast, PICK1 interaction was unaffected by GluR2 C-terminal tyrosine phosphorylation (Fig. 4C). The interaction of the GluR2Y876F mutant with GRIP1 (Fig. 4D), GRIP2 (Fig. 4E), and PICK1 (Fig. $4 F$ ) was not influenced by coexpression with Lyn. In extracellular solution, indicating that the agonist-induced PTK activation pathway was independent of calcium influx. In addition, the Src family PTK-specific inhibitor PP2 blocked the basal and GluR agonist-induced tyrosine phosphorylation of GluR2 C terminus, indicating that Src family PTKs phosphorylated GluR2 in vivo (Fig. 5B). PP2 inhibition effects on tyrosine phosphorylation of the GluR2 C terminus were observed in both surfaceexpressed fraction and total cell lysates (Fig. $5 C$ ).

\section{Tyrosine phosphorylation affected GluR2 localization and trafficking pattern}

To analyze the functional effect of tyrosine phosphorylation of GluR2, we examined the membrane trafficking of GFP-tagged wild type (GFP-GluR2) and the tyrosine phosphorylation mutant (GFP-GluR2Y876F) GluR2 subunits. These constructs were transfected into low-density hippocampal cultured neurons (Fig. 6A) (Goslin and Banker, 1991) or high-density cortical cultured neurons (Fig. 6B,C) (Xia et al., 1996) and examined 6-7 d after transfection. The total GFP fluorescence intensity of the wildtype and mutant GluR2 subunits in dendrites was similar, and both wild-type and mutant GluR2 subunits clustered at synapses as demonstrated by colocalization with the presynaptic marker synaptophysin (Fig. 6A). However, when quantified, the synaptic targeting of the mutant GluR2 was significantly decreased compared with wild type (Fig. $6 A, B$ ).

We then tested the surface expression of the GFP-GluR2 and GFP-GluR2YF subunits. Transfected cortical neurons were stained live with anti-GFP antibodies $\left(10^{\circ} \mathrm{C}, 20 \mathrm{~min}\right)$, washed, then fixed with $4 \%$ paraformaldehyde, $4 \%$ sucrose in PBS, and blocked with $10 \%$ normal donkey serum $\left(4^{\circ} \mathrm{C}\right.$, overnight). AntiGFP antibodies were then stained with $\mathrm{Cy} 3$-conjugated antirabbit IgG. The ratio of Cy3-red to GFP-green signals indicate the ratio of surface expression of the GFP-GluR2 to total GFP expression. In these live-staining experiments with anti-GFP antibodies, the tyrosine phosphorylation site mutant showed significantly reduced surface expression compared with wild type. 
These data suggest that tyrosine phosphorylation of GluR2 regulates trafficking to the cell surface or helps to maintain the surface expression of GluR2 (Fig. 6C).

\section{Tyrosine phosphorylation-dependent GluR2 internalization}

Finally, the effects of mutation of tyrosine 876 on agonist-induced internalization of GFP-GluR2 and PP2 on agonist-induced internalization of endogenous GluR1 were examined. Recent studies have revealed that AMPA receptor endocytosis is increased in AMPA or NMDA treatment of neurons (Beattie et al., 2000; Lin et al., 2000; Man et al., 2000; Carroll et al., 2001). To measure receptor internalization, surface GFP-GluR2 and GFP-GluR2YF in transfected cortical neurons were labeled by live-staining with anti-GFP antibodies, and the neurons were then incubated with and without $100 \mu \mathrm{M}$ AMPA for $10 \mathrm{~min}$ or $50 \mu \mathrm{M}$ NMDA for 2-3 min in gliaconditioned media (totally incubated for $10 \mathrm{~min}$ at $37^{\circ} \mathrm{C}$ ). After incubation, the cortical neurons were fixed, and the remaining surface anti-GFP antibodies were blocked by incubation with anti-rabbit IgG goat antibody $\mathrm{F}\left(\mathrm{ab}^{\prime}\right) 2$ fragment. The fixed neurons were then permeabilized, and the internalized anti-GFP antibodies were visualized by staining with Cy3conjugated anti-rabbit IgG antibodies (Fig. 7A). The ratio of average intensity of internalized anti-GFP antibodies (Cy3-red intensity) to that of total-expressing GFP (GFP-green intensity) was calculated. The AMPA- and NMDA-induced internalization was normalized to the control internalization for wild-type and mutant GluR2. The results showed that both AMPA and NMDA stimulation enhanced the internalization of GFP-GluR2, whereas the internalization of the mutant GFPGluR2YF subunit was not increased by agonist stimulation. In contrast, the total GFP-GluR2 fluorescence intensity in dendrites was similar for GFP-GluR2 and GFP-GluR2YF (Fig. 7A). In addition, AMPA- and NMDA-induced internalization of GFP-GluR2 was inhibited by Src family PTK-specific inhibitor PP2 treatment $(20 \mu \mathrm{M})$ but not by inactive structural analog PP3 treatment $(20 \mu \mathrm{M})$ (Fig. $7 B)$. Moreover, PP2 also inhibited AMPAand NMDA-induced internalization of endogenous surface GluR1 subunits that are associated with GluR2 in hippocampal neurons (Fig. 7C). These observations strongly suggested that PTK activity is required for stimulation-dependent internalization of the AMPA receptor and that tyrosine phosphorylation of GluR2 by Src
A

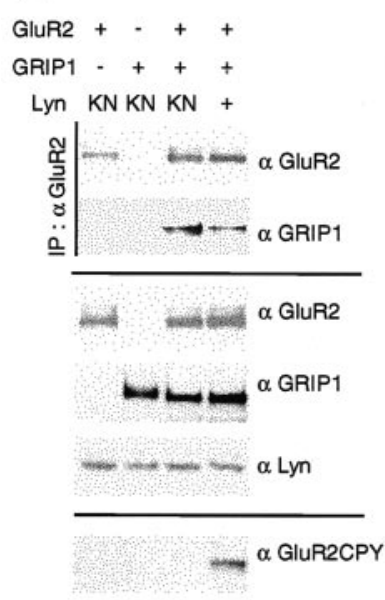

D

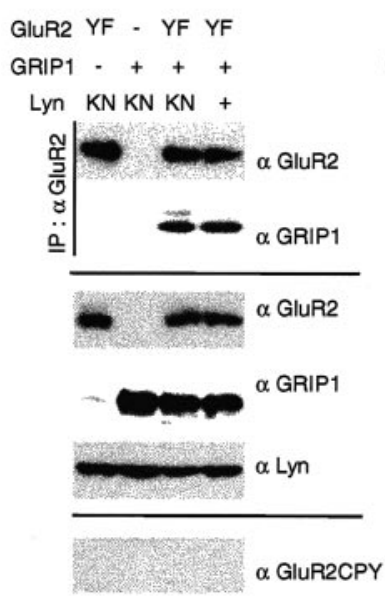

G

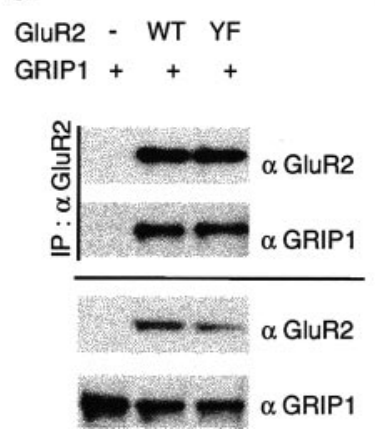

B

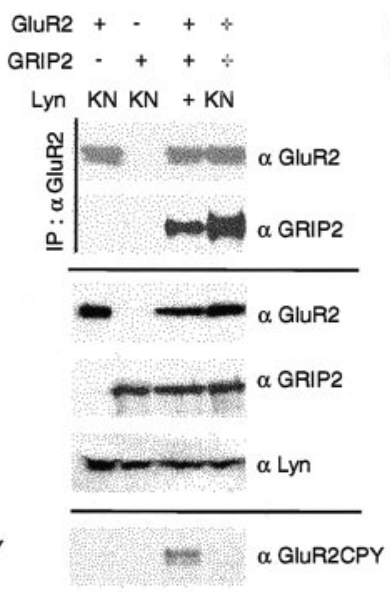

$E$

GluR2 YF - YF YF GRIP2 - + + + Lyn $\mathrm{KN} \mathrm{KN}+\mathrm{KN}$

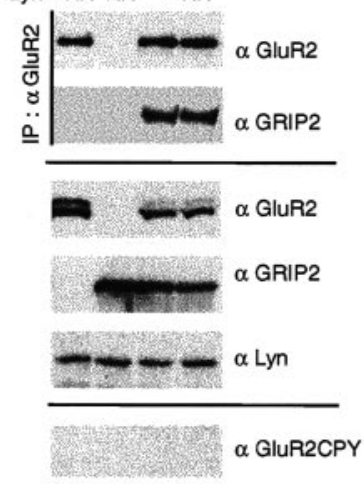

$\mathrm{H}$

GluR2 - WT YF GRIP2 + + +

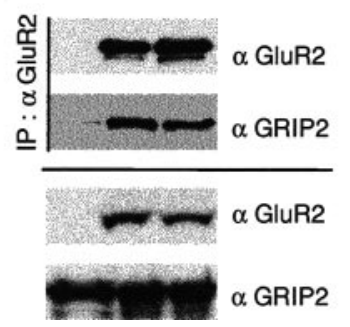

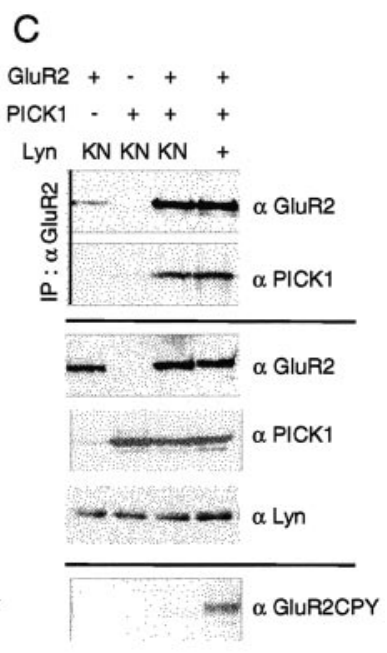

F

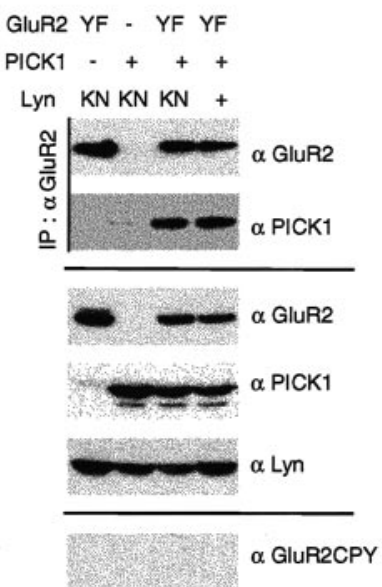

Figure 4. GluR2 C-terminal tyrosine phosphorylation differently regulated its interaction with GRIP1/2 and PICK1. A-F, The regulation of the association of GluR2 with its interacting proteins GRIP1, GRIP2, and PICK1 by tyrosine phosphorylation was analyzed in transfected HEK cells. GluR2 was immunoprecipitated with anti-GluR2 antibodies from lysates of HEK 293T cells transfected with plasmids encoding GluR2 wild type $(A-C)$ or Y876F mutant $(D-F)$, wild-type or kinase-negative (KN) form of Src family PTK Lyn, and GRIP1 $(A, D)$, GRIP2 $(B, E)$, or PICK1 $(C, F)$. Anti-GluR2 coimmunoprecipitates from cell lysates were immunoblotted with each antibody (top). Expression of each protein was confirmed by protein immunoblots of cell lysates probed with anti-GluR2, anti-GRIP1 $(A, D)$, anti-GRIP2 (B,E), anti-PICK1 (C,F) or anti-Lyn antibodies (middle). Tyrosine phosphorylation of the GluR2 $C$ terminus was checked by protein immunoblots of cell lysates probed with anti-GluR2CPY antibodies (bottom). $G-I$, The equal binding of GluR2 wild type and Y876F mutant with GRIP1 (G), GRIP2 (H), and PICK1 ( $/$ ) was analyzed in transfeceted HEK cells. Anti-GluR2 coimmunoprecipitation (top) and protein expression (bottom) are shown. 
A

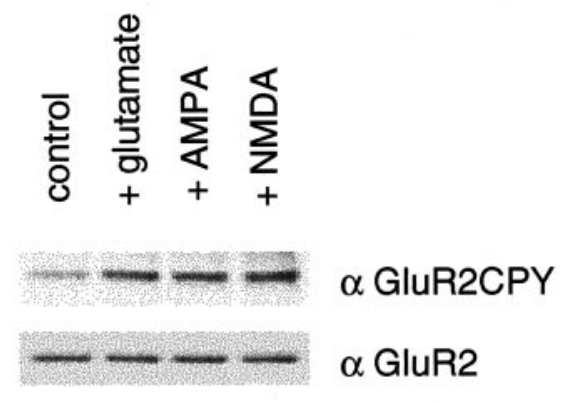

B
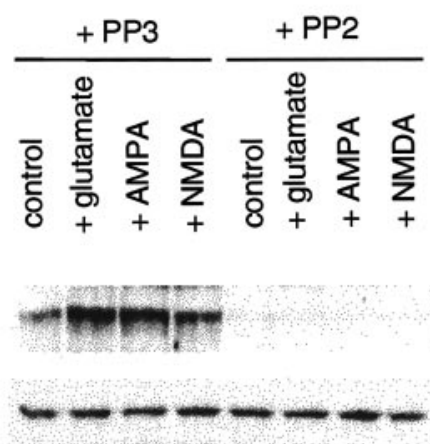

$\alpha$ GluR2CPY

$\alpha$ GluR2
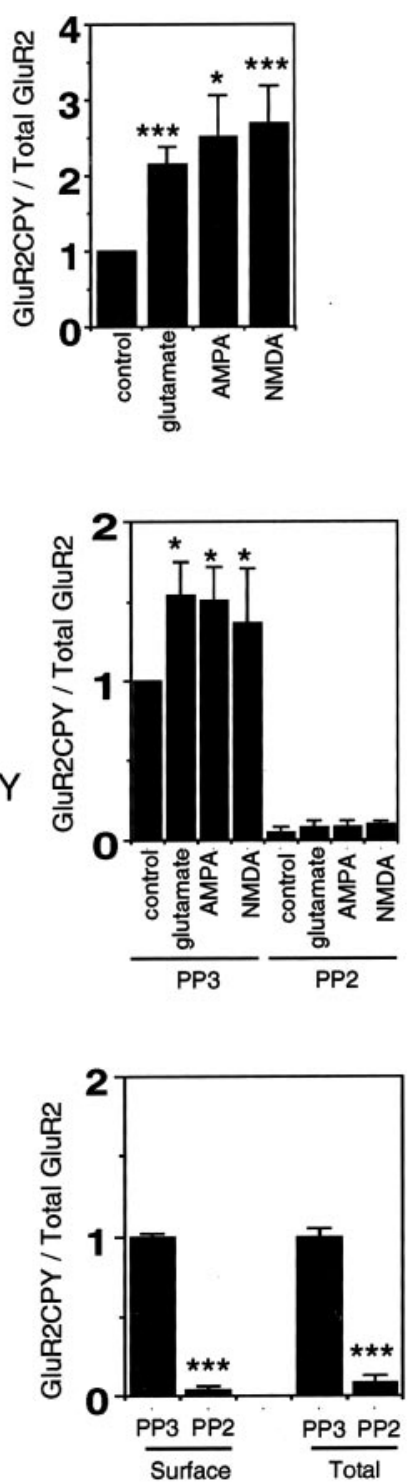

Figure 5. Regulation of GluR2 C-terminal tyrosine phosphorylation in cultured cortical neurons. A, C-terminal tyrosine phosphorylated GluR2 in lysates from primary cortical cultures (culture DIV, 3-4 weeks) stimulated with $100 \mu \mathrm{m}$ glutamate, $100 \mu \mathrm{m}$ AMPA, or $50 \mu \mathrm{M}$ NMDA for $10 \mathrm{~min}$. Cell lysates were immunoblotted with anti-GluR2CPY or anti-GluR2 antibodies [ $n=8$ (control), $n=8(+$ glutamate),$n=8(+$ AMPA), $n=5(+\mathrm{NMDA})$, respectively]. $B$, The effect of Src family PTK-specific inhibitor PP2 $(20 \mu \mathrm{m})$ or the inactive structural analog PP3 $(20 \mu \mathrm{m})$ on GluR agonist-induced GluR2 C-terminal tyrosine phosphorylation. Cortical cultured neurons were stimulated with $100 \mu \mathrm{m}$ glutamate, $100 \mu \mathrm{m} \mathrm{AMPA}$, or $50 \mu \mathrm{m}$ NMDA for 10 min $(n=4$, respectively). C, The effect of PP2 $(20 \mu \mathrm{m})$ or PP3 $(20 \mu \mathrm{m})$ on surface and total GluR2 C-terminal tyrosine phosphorylation. Cortical culture neurons were treated with PP2 or PP3 for $1 \mathrm{hr}$, and surface-expressed proteins were biotinylated and precipitated with NeutrAvidin beads ( $n=4$, respectively). Ratios of GluR2 C-terminal tyrosine phosphorylation to total GluR2 are shown. Data are mean \pm SEM; $t$ test; ${ }^{*} p<0.05,{ }^{* * *} p<0.001$, compared with control.

family PTKs is required for AMPA- and NMDA-induced internalization of GluR2.

\section{Discussion}

Recent studies have shown that glutamate receptor phosphorylation is critical for the regulation of synaptic transmission and synaptic plasticity (Song and Huganir, 2002). Previous reports have focused on serine and threonine phosphorylation of AMPA receptors, however, the role of tyrosine phosphorylation of AMPA receptors in the regulation of receptor function has not been investigated. In this study, we demonstrated that the GluR2 subunit of AMPA receptors was phosphorylated on tyrosine 876 in its $\mathrm{C}$ terminus in vitro and in vivo. This site was phosphorylated by Src family PTKs in transfected heterologous cells and in neurons in situ. In addition, phosphorylation of tyrosine 876 regulated AMPA receptor surface expression and synaptic targeting of GluR2. Src family PTKs have previously been shown to regulate excitatory synaptic transmission (Soderling and Derkach, 2000), and phosphorylation of GluR2 on tyrosine 876 may mediate some of these effects. Although the sequence around tyrosine 876 in GluR2 is a general nonreceptor-type PTK target, we found that other nonreceptor-type PTKs, such as Fak and Pyk2, did not phosphorylate GluR2 in transfected HEK 293T cells.

Our data indicated that although GluR2 and -3 are tyrosine phosphorylated, we could not detect tyrosine phosphorylation of GluR1 and -4. However, several tyrosine residues are conserved within the intracellular region of the AMPA receptor subunits GluR1-4, and it is possible that these sites are phosphorylated at low stoichiometries in vivo. In fact, we have previously shown that GluR1 could be tyrosine phosphorylated by overexpression of $\mathrm{v}$-Src in transfected HEK 293 cells (Moss et al., 1993). Furthermore, a GluR2 $\Delta 21$ mutant, which eliminates the three $\mathrm{C}$-terminal tyrosine residues (Y869, Y873, and Y876), was still significantly tyrosine phosphorylated by Src family PTKs in transfected HEK 293T cells (data not shown). These observations indicate that GluR2 tyrosine 570 between TMD1 and - 2 or GluR2 tyrosine 837 at just after TMD 4, tyrosines that are conserved among AMPA receptor subunits GluR1-4, may also be phosphorylated in vivo. A recent study revealed the role of tyrosine phosphorylation of GluR2 in insulin-stimulated AMPA receptor endocytosis and LTD (Ahmadian et al., 2004). Our phosphotyrosine-specific antibodies (antiGluR2CPY) did not detect enhancements of insulin $(0.5 \mu \mathrm{M})$-stimulated tyrosine phosphorylation of GluR2 in cortical neurons, suggesting that insulin stimulation regulates phosphorylation of tyrosines besides tyrosine 876. AMPA-induced GluR2 internalization was detected in their mutant, the C-terminal three-tyrosine residues of which were mutated into alanines, whereas our data showed Y876F mutant prevented AMPA-induced GluR2 internalization. This may depend on the difference of observed regions; namely, they measured the internalization in the whole region of soma and dendrites in a transfected neuron, whereas we focused dendritic receptor internalization, which is more important for glutamatergic synaptic transmission.

Mutation of tyrosine 876 affected the steady-state trafficking of GluR2 in cultured neurons. The Y876F mutant of GFP-GluR2 in transfected cortical neurons did not accumulate at synapses and had a diffuse distribution compared with the wild-type re- 
ceptor. In addition, the steady-state surface expression of Y876F GluR2 mutant was reduced, but significant levels of surface receptor were detected. These findings suggest that phosphorylation of GluR2 at tyrosine 876 regulates the steady-state synaptic trafficking of GluR2. Furthermore, our data suggest that phosphorylation at tyrosine 876 by Src family PTKs is required for the regulated internalization of the AMPA receptor. These experiments used overexpressed recombinant GluR2 subunits, a common technique used by us and many other groups. This exogenous GluR2 expression makes homomeric receptor, which is different from endogenous heteromeric AMPA receptor, but it is useful to elucidate subunit-specific properties of AMPA receptor trafficking (Malinow and Malenka, 2002). The different surface delivery between GluR2 wild type and YF mutant may depend on some mechanism in steady-state synaptic trafficking pathway. In contrast, agonistinduced AMPA receptor internalization is a rapid change of preexisting surface receptors. It is somewhat surprising that mutation of tyrosine 876 decreases surface expression of GluR2 if tyrosine phosphorylation is required for agonist-stimulated internalization. However, it is not clear how important agonist-induced internalization is for regulating the steady-state surface levels of the receptor. As we and others have shown, the mechanisms regulating steady-state GluR2 expression may be quite different from those regulating more dynamic changes in receptor levels. It is possible that tyrosine 876 regulates some other step that modulates receptor trafficking at steady state. Mutation of tyrosine 876 and Src family PTK-specific inhibitor PP2 treatment eliminates AMPAand NMDA-induced internalization of GluR2 in neurons. In contrast to these results, previous studies have reported that deletion of the last 15 amino acids of GluR2 did not block AMPA-induced internalization in HEK 293 cells (Lin et al., 2000). It is not clear why this deletion did not block AMPAinduced internalization in this previous study, but it is likely that internalization in HEK 293 cells and neurons have different determinants. In addition, a previous study reported that the general PTK inhibitor genistein did not affect AMPA- and NMDAinduced internalization of GluR1 in cultured neurons (Beattie et al., 2000), whereas our data showed that the Src family PTKspecific inhibitor PP2 blocked AMPA- and NMDA-induced internalization of GluR2. The lack of genistein inhibition of GluR2 internalization in this previous study may be because genistein is a poor inhibitor of the Src family PTKs at the concentration used $(1 \mu \mathrm{M})$.

AMPA- and NMDA-induced tyrosine phosphorylation of GluR2 C terminus occurred in calcium-free extracellular solution
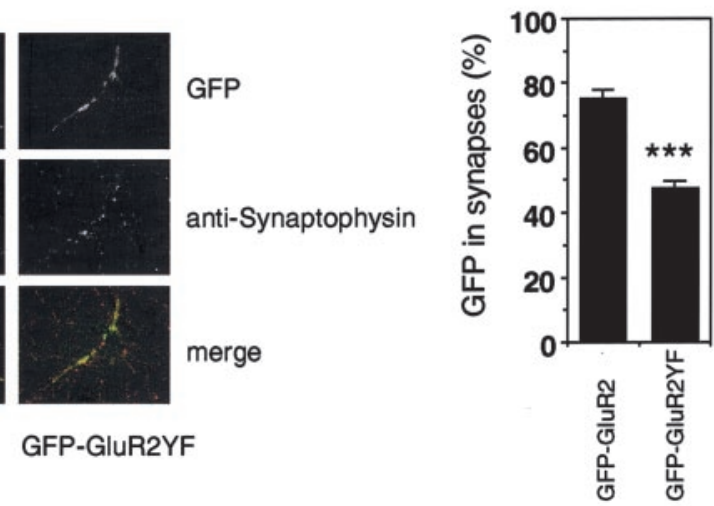

B

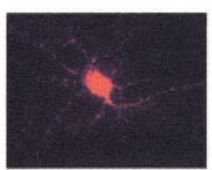

GFP-GluR2
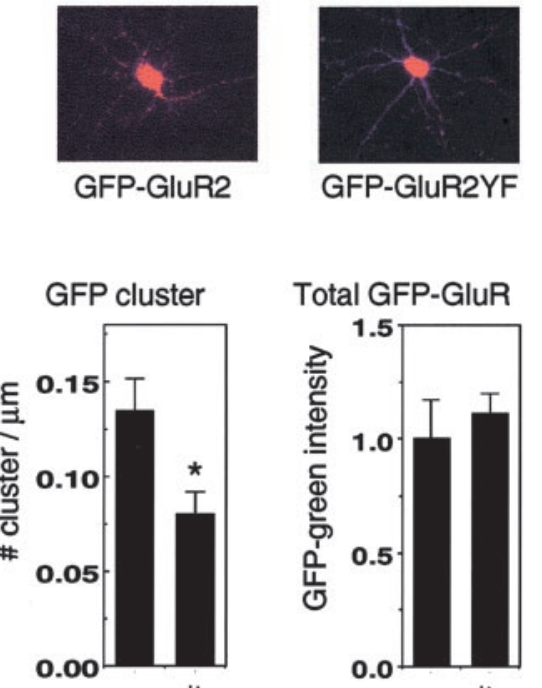

C
Total GFP-GluR
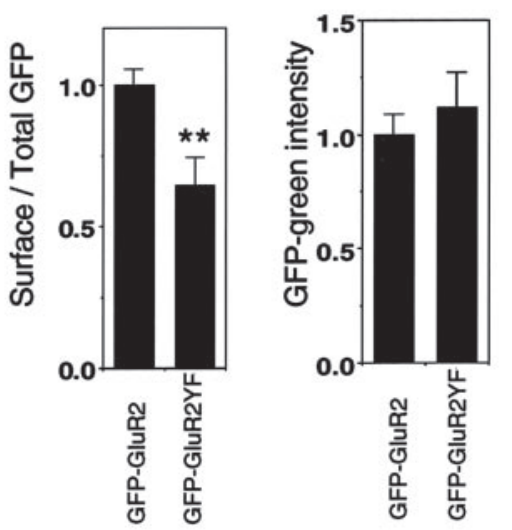

Figure 6. Phosphorylation of tyrosine 876 regulated clustering and surface expression of GFP-GluR2 in cortical neurons. $A$, Colocalization of GFP-GluR2 and GFP-GluR2YF mutant with synaptophysin in dendrites of transfected low-density hippocampal essions in the dendrites ( $n=10$, respectively; $t$ test; $p>0.5$ ) of GFP-GluR2 and GFP-GluR2YF mutant in transfected cortical (right; $n=10$, respectively; $t$ test; $p>0.5$ ) in GFP-GluR2- or GFP-GluR2YF-transfected cortical neurons. Data are mean \pm SEM; $t$ test; ${ }^{*} p<0.05,{ }^{* *} p<0.01,{ }^{* * *} p<0.001$, compared with control.

containing $5 \mu \mathrm{M}$ TTX, indicating that tyrosine phosphorylation of the GluR2 C terminus appears to be independent of calcium influx. Agonist binding to AMPA receptors has previously been shown to regulate AMPA receptor-associated Lyn kinase activity in the absence of extracellular calcium (Hayashi et al., 1999), suggesting there is a conformational link between agonist binding, activation of Lyn, and tyrosine phosphorylation of the receptor. This is reminiscent of the agonist-induced phosphorylation of G-protein-coupled receptors that can also occur in the absence of calcium. Interestingly, phosphorylation of G-protein-coupled receptors regulates their interaction with the arrestin proteins and thus regulates receptor endocytosis (Luttrell and Lefkowitz, 2002; Sorkin and von Zastrow, 2002). In contrast to AMPA- and NMDA-induced tyrosine phosphorylation of GluR2, AMPA- 
A

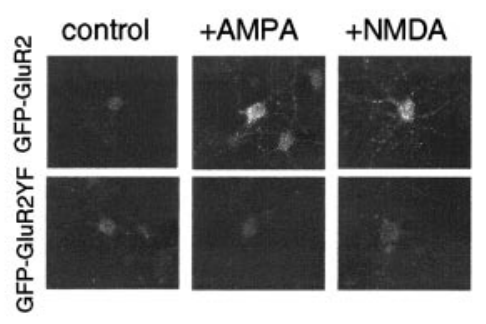

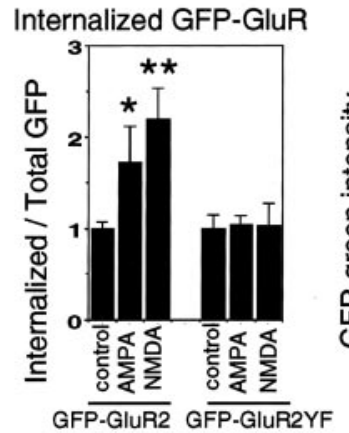

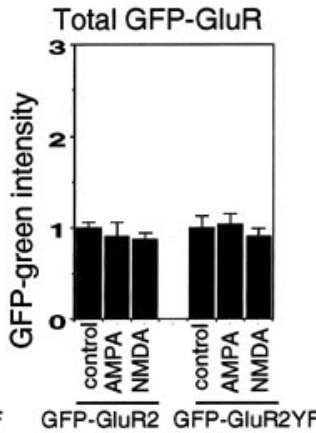

B

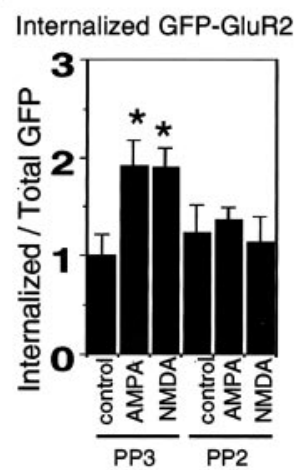

Total GFP-GluR2

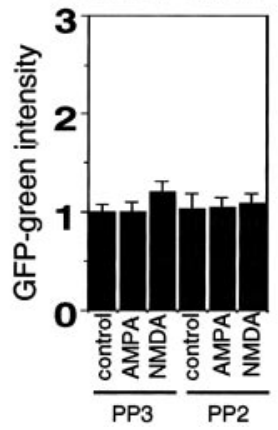

C

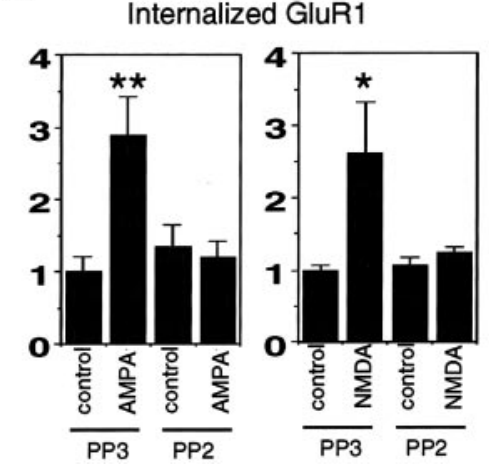

Figure 7. Phosphorylation of tyrosine 876 is required for regulated internalization of GFP-GluR2 in cultured neurons. A, AMPAand NMDA-induced internalization of GFP-GluR2 and GFP-GluR2YF. Typical patterns of GluR agonist stimulation induced internalization of surface GFP in GFP-GluR2- or GFP-GluR2YF-transfected cortical neurons (left). The ratio of fluorescence intensities of internalized anti-GFP antibodies (visualized by Cy3-conjugated anti-rabbit lgG) to total GFP expression (green fluorescent signal of GFP) are shown (middle) (left three bars: $n=7, n=6, n=8$, respectively; $F=4.4 ; p<0.05$; right three bars: $n=8, n=$ $8, n=8$, respectively; $F=0.011 ; p>0.98$ ). Total GFP expressions in the dendrites of GFP-GluR2 and GFP-GluR2YF mutant in transfected cortical neurons are shown (right) (left three bars: $n=7, n=6, n=8$, respectively; $F=0.523 ; p>0.6$; right three bars: $n=8, n=8, n=8$, respectively; $F=0.34 ; p>0.7)$. $B$, The effect of Src family PTK-specific inhibitor PP2 (20 $\mu \mathrm{M})$ or inactive structural analog PP3 $(20 \mu \mathrm{m})$ on AMPA- and NMDA-induced internalization of GFP-GluR2. The ratio of fluorescence intensities of internalized anti-GFP antibodies (visualized by Cy3-conjugated anti-rabbit lgG) and total GFP expression (green fluorescent signal of GFP) are shown (left) ( six bars; $n=5, n=10, n=9, n=5, n=9, n=11$, respectively; $F=2.7 ; p<0.05$ ). Total GFP expression in the dendrites of GFP-GluR2 in transfected cortical neurons are shown (right) (six bars; $n=4, n=12, n=$ $10, n=6, n=9, n=11$, respectively; $F=0.44 ; p>0.8)$. C, The effect of PP2 (20 $\mu \mathrm{M})$ or PP3 (20 $\mu \mathrm{M})$ on AMPA- and NMDA-induced internalization of endogenous GluR1 in hippocampal neurons. The ratios of fluorescence intensities of internalized anti-GluR1 $\mathrm{N}$ terminus antibodies (visualized by (y3-conjugated anti-rabbit lgG) are shown (AMPA: four bars; $n=9, n=9, n=$ $7, n=9$, respectively; $F=6.344 ; p<0.01$; NMDA: four bars; $n=7, n=6, n=9, n=7$, respectively; $F=5.618 ; p<0.01$ ). Data are mean \pm SEM; ANOVA; ${ }^{*} p<0.05,{ }^{* *} p<0.01$, compared with control.

and NMDA-induced AMPA receptor endocytosis has been reported to require extracellular calcium influx (Beattie et al., 2000; Lin et al., 2000; Carroll et al., 2001). These results suggest that although phosphorylation of tyrosine 876 by Src family PTKs may be required for AMPA receptor endocytosis, it is not sufficient, and an additional calcium-dependent step is required for endocytosis. Moreover, our results do not eliminate the possibility that tyrosine phosphorylation of other proteins by Src family PTKs may be required for receptor endocytosis.

The molecular mechanisms underlying the regulation of endocytosis by tyrosine 876 phosphorylation appear to involve the regulation of the interaction of GluR2 with its interacting proteins. Several studies have shown that the $\mathrm{C}$-terminal amino acids adjacent to tyrosine 876 are required for binding to PDZ domaincontaining proteins GRIP1/2 and PICK1, which regulate receptor trafficking (Chung et al., 2000, 2003; Daw et al., 2000; Matsuda et al., 2000; Osten et al., 2000; Xia et al., 2000; Kim et al., 2001). Our studies revealed that tyrosine phosphorylation of GluR2 appear to regulate the binding of GluR2 to GRIP1 and GRIP2, but not to PICK1. Previous studies have shown that protein kinase $\mathrm{C}$ phosphorylation of serine 880 , four amino acids away from tyrosine 876 , regulates binding to GRIP1/2 and PICK 1 and regulates endocytosis of AMPA receptors. A variety of studies have indicated that GRIP1/2 enhance receptor surface expression, whereas PICK1 promotes receptor internalization (Chung et al., 2000, 2003; Daw et al., 2000; Matsuda et al., 2000; Osten et al., 2000; Xia et al., 2000; Kim et al., 2001). Thus, tyrosine phosphorylation of the GluR2 C terminus may destabilize the GluR2 interaction with GRIP1/2 and allow more GluR2 binding to PICK1, promoting the receptor internalization.

Finally, several studies have suggested that AMPA receptor endocytosis is critical for LTD in the hippocampus and cerebellum (Ito, 2002; Malinow and Malenka, 2002). Recently, we and others have provided strong evidence that phosphorylation of GluR2 on serine 880 and the interaction of GluR2 with PICK1 are critical for cerebellar LTD (Chung et al., 2003). The regulatory role of Src family PTKs on AMPA receptor synaptic transmission has not been well studied, but PTK inhibitors have been shown to block hippocampal and cerebellar LTD, forms of plasticity that involve receptor endocytosis, suggesting the importance of PTK activity in the AMPA receptor endocytic pathway. These results fit well with our data presented here. The data presented here suggests that tyrosine phosphorylation of the GluR2 C terminus adds a novel level of regulation to AMPA receptor membrane trafficking and indicates that tyrosine phosphorylation of AMPA receptors may contribute to stimulation-dependent long-term plasticity at excitatory synapses.

\section{References}

Ahmadian G, Ju W, Liu L, Wyszynski M, Lee SH, Dunah AW, Taghibiglou C, Wang Y, Lu J, Wong TP, Sheng M, Wang YT (2004) Tyrosine phosphorylation of GluR2 is required for insulin-stimulated AMPA receptor endocytosis and LTD. EMBO J 23:1040-1050.

Banke TG, Bowie D, Lee H, Huganir RL, Schousboe A, Traynelis SF (2000) Control of GluR1 AMPA receptor function by cAMP-dependent protein kinase. J Neurosci 20:89-102.

Barria A, Derkach V, Soderling T (1997) Identification of the Ca2+/ calmodulin-dependent protein kinase II regulatory phosphorylation site in the alpha-amino-3-hydroxyl-5-methyl-4-isoxazole-propionate-type glutamate receptor. J Biol Chem 272:32727-32730.

Beattie EC, Carroll RC, Yu X, Morishita W, Yasuda H, von Zastrow M, Malenka RC (2000) Regulation of AMPA receptor endocytosis by a signaling mechanism shared with LTD. Nat Neurosci 3:1291-1300.

Boxall AR, Lancaster B (1998) Tyrosine kinases and synaptic transmission. Eur J Neurosci 10:2-7. 
Carroll RC, Beattie EC, von Zastrow M, Malenka RC (2001) Role of AMPA receptor endocytosis in synaptic plasticity. Nat Rev Neurosci 2:315-324.

Chung HJ, Xia J, Scannevin RH, Zhang X, Huganir RL (2000) Phosphorylation of the AMPA receptor subunit GluR2 differentially regulates its interaction with PDZ domain-containing proteins. J Neurosci 20:7258-7267.

Chung HJ, Steinberg JP, Huganir RL, Linden DJ (2003) Requirement of AMPA receptor GluR2 phosphorylation for cerebellar long-term depression. Science 300:1751-1755.

Daw MI, Chittajallu R, Bortolotto ZA, Dev KK, Duprat F, Henley JM, Collingridge GL, Isaac JT (2000) PDZ proteins interacting with C-terminal GluR2/3 are involved in a PKC-dependent regulation of AMPA receptors at hippocampal synapses. Neuron 28:873-886.

Derkach V, Barria A, Soderling TR (1999) Ca2 +/calmodulin-kinase II enhances channel conductance of alpha-amino-3-hydroxy-5-methyl-4isoxazolepropionate type glutamate receptors. Proc Natl Acad Sci USA 96:3269-3274.

Esteban JA, Shi SH, Wilson C, Nuriya M, Huganir RL, Malinow R (2003) PKA phosphorylation of AMPA receptor subunits controls synaptic trafficking underlying plasticity. Nat Neurosci 6:136-143.

Goslin K, Banker G (1991) Culturing nerve cells. London: MIT.

Grant SGN, O’Dell TJ, Karl KA, Stein PL, Soriano P, Kandel ER (1992) Impaired long-term potentiation, spatial learning, and hippocampal development in fyn mutant mice. Science 258:1903-1910.

Hayashi T, Umemori H, Mishina M, Yamamoto T (1999) The AMPA receptor interacts with and signals through the protein tyrosine kinase Lyn. Nature 397:72-76.

Hollmann M, Heinemann S (1994) Cloned glutamate receptors. Annu Rev Neurosci 17:31-108.

Ito M (2002) The molecular organization of cerebellar long-term depression. Nat Rev Neurosci 3:896-902.

Kameyama K, Lee HK, Bear MF, Huganir RL (1998) Involvement of a postsynaptic protein kinase A substrate in the expression of homosynaptic long-term depression. Neuron 21:1163-1175.

Kim CH, Chung HJ, Lee HK, Huganir RL (2001) Interaction of the AMPA receptor subunit GluR2/3 with PDZ domains regulates hippocampal long-term depression. Proc Natl Acad Sci USA 98:11725-11730.

Kitazawa H, Yagi T, Miyakawa T, Niki H, Kawai N (1998) Abnormal synaptic transmission in the olfactory bulb of Fyn-kinase-deficient mice. J Neurophysiol 79:137-142.

Lee HK, Kameyama K, Huganir RL, Bear MF (1998) NMDA induces longterm synaptic depression and dephosphorylation of the GluR1 subunit of AMPA receptors in hippocampus. Neuron 21:1151-1162.

Lee HK, Barbarosie M, Kameyama K, Bear MF, Huganir RL (2000) Regulation of distinct AMPA receptor phosphorylation sites during bidirectional synaptic plasticity. Nature 405:955-959.

Lee HK, Takamiya K, Han JS, Man H, Kim CH, Rumbaugh G, Yu S, Ding L, He C, Petralia RS, Wenthold RJ, Gallagher M, Huganir RL (2003) Phosphorylation of the AMPA receptor GluR1 subunit is required for synaptic plasticity and retention of spatial memory. Cell 112:631-643.

Liao D, Zhang X, O’Brien R, Ehlers MD, Huganir RL (1999) Regulation of morphological postsynaptic silent synapses in developing hippocampal neurons. Nat Neurosci 2:37-43.

Lin JW, Ju W, Foster K, Lee SH, Ahmadian G, Wyszynski M, Wang YT, Sheng
M (2000) Distinct molecular mechanisms and divergent endocytotic pathways of AMPA receptor internalization. Nat Neurosci 3:1282-1290.

Luttrell LM, Lefkowitz RJ (2002) The role of $\beta$-arrestins in the termination and transduction of G-protein-coupled receptor signals. J Cell Sci 115:455-465

Malinow R, Malenka RC (2002) AMPA receptor trafficking and synaptic plasticity. Annu Rev Neurosci 25:103-126.

Mammen AL, Kameyama K, Roche KW, Huganir RL (1997) Phosphorylation of the alpha-amino-3-hydroxy-5-methylisoxazole 4-propionic acid receptor GluR1 subunit by calcium/calmodulin-dependent kinase II. J Biol Chem 272:32528-32533.

Man HY, Lin JW, Ju WH, Ahmadian G, Liu L, Becker LE, Sheng M, Wang YT (2000) Regulation of AMPA receptor-mediated synaptic transmission by clathrin-dependent receptor internalization. Neuron 25:649-662.

Matsuda S, Launey T, Mikawa S, Hirai H (2000) Disruption of AMPA receptor GluR2 clusters following long-term depression induction in cerebellar Purkinje neurons. EMBO J 19:2765-2774.

Miyakawa T, Yagi T, Kitazawa H, Yasuda M, kawai N, Tsuboi K, Niki H (1997) Fyn-kinase as a determinant of ethanol sensitivity: relation to NMDA-receptor function. Science 278:698-701.

Moss SJ, Blackstone CD, Huganir RL (1993) Phosphorylation of recombinant non-NMDA glutamate receptors on serine and tyrosine residues. Neurochem Res 18:105-110.

O'Dell TJ, Kandel ER, Grant SGN (1991) Long-term potentiation in the hippocampus is blocked by tyrosine kinase inhibitors. Nature 353:558-560.

Osten P, Khatri L, Perez JL, Kohr G, Giese G, Daly C, Schulz TW, Wensky A, Lee LM, Ziff EB (2000) Mutagenesis reveals a role for ABP/GRIP binding to GluR2 in synaptic surface accumulation of the AMPA receptor. Neuron 27:313-325.

Roche KW, Tingley WG, Huganir RL (1994) Glutamate receptor phosphorylation and synaptic plasticity. Curr Opin Neurobiol 4:383-388.

Roche KW, O’Brien RJ, Mammen AL, Bernhardt J, Huganir RL (1996) Characterization of multiple phosphorylation sites on the AMPA receptor GluR1 subunit. Neuron 16:1179-1188.

Soderling TR, Derkach VA (2000) Postsynaptic protein phosphorylation and LTP. Trends Neurosci 23:75-80.

Song I, Huganir RL (2002) Regulation of AMPA receptors during synaptic plasticity. Trends Neurosci 25:578-588

Songyang Z (2001) Analysis of protein kinase specificity by peptide libraries and prediction of in vivo substrates. Methods Enzymol 332:171-183.

Songyang Z, Cantley LC (1998) The use of peptide library for the determination of kinase peptide substrates. Methods Mol Biol 87:87-98.

Sorkin A, von Zastrow M (2002) Signal transduction and endocytosis: close encounters of many kinds. Nat Rev Mol Cell Biol 3:600-614.

Swope SL, Moss SI, Raymond LA, Huganir RL (1999) Regulation of ligandgated ion channels by protein phosphorylation. Adv Second Messenger Phosphoprotein Res 33:49-78.

Xia J, Chung HJ, Wihler C, Huganir RL, Linden DJ (2000) Cerebellar longterm depression requires PKC-regulated interactions between GluR2/3 and PDZ domain-containing proteins. Neuron 28:499-510.

Xia Z, Dudek H, Miranti CK, Greenberg ME (1996) Calcium influx via the NMDA receptor induces immediate early gene transcription by a MAP kinase/ERK-dependent mechanism. J Neurosci 16:5425-5436. 